\title{
Investigasi Patahan Spring Bolt pada Front Leaf Spring
}

\author{
Wahyu Anhar ${ }^{1^{*}}$ \\ ${ }^{1}$ Jurusan Teknik Mesin, Politeknik Negeri Balikpapan \\ *email:wahyu.anhar@poltekba.ac.id
}

\begin{abstract}
The failure of spring bolt in front leaf spring dump truck unit was investigated. Root cause of spring bolt fracture was determined from fracture surface, and condition of spring bolt. The failure of spring bolt was caused by torsional shear. The load that been caused fracture is single-overload. Supporting factors of failure were caused by no lubrication, road condition, and unit load. Position of failure was happened in groove and close by threads, because that area possess a high stress concentration.
\end{abstract}

Keywords: spring bolt, fracture surface, torsional shear, single-overload

\begin{abstract}
Abstrak
Penyebab kegagalan spring bolt pada front leaf spring unit dump truck telah dilakukan investigasi. Penyebab patahan spring bolt ditentukan berdasarkan bentuk permukaan patahan (fracture surface), dan kondisi spring bolt. Spring bolt mengalami perpatahan yang disebabkan adanya torsional shear. Pembebanan yang telah menyebabkan perpatahan adalah pembebanan secara single-overload. Faktor-faktor penunjang patahan dikarenakan tidak adanya pelumasan, kondisi jalan, dan muatan unit. Posisi patahan terjadi di groove dan dekat ulir karena bagian tersebut memiliki konsentrasi tegangan yang tinggi.
\end{abstract}

Kata kunci: spring bolt, fracture surface, torsional shear, single-overload

\section{Pendahuluan}

Suspensi merupakan mekanisme yang menghubungkan antara roda dengan body/frame kendaraan. Fungsi suspensi adalah sebagai pendukung/penopang berat unit, meredam dan memperhalus kejutan yang diterima oleh roda akibat bentuk permukaan jalan, serta meningkatkan kestabilan mengemudi. Suspensi dibagi menjadi 3 macam kelompok, antar lain independent, dependent dan semi-independent suspension [1]. Dependent suspensions atau juga rigid axle digunakan untuk rigid linkage antara dua roda yang dihubungkan dengan satu axle. Salah satu penggunaan rigid axle sebagai front suspension adalah rigid axle dengan leaf spring.

Artikel ini disusun berdasarkan studi kasus terkait patahnya spring bolt pada front leaf spring. Unit yang mengalami permasalahan patahnya spring bolt pada front leaf spring adalah unit dump truck Scania P$420 \mathrm{CB} 8 \times 4 \mathrm{EHZ}$. Unit tersebut berfungsi untuk membawa muatan berupa batubara di lokasi pertambangan. Gambar 1 menunjukkan unit yang mengalami permasalahan patahnya spring bolt pada front leaf spring. Akar penyebab patahnya spring bolt harus diketahui sehingga dapat mencegah terjadinya breakdown unit yang berdampak terhadap produktivitas dan finansial.

Komponen spring bolt yang mengalami perpatahan seperti ditunjukkan dalam Gambar 2. Data lapangan dan bentuk patahan dianalisa untuk dapat menentukan akar penyebab patahnya spring bolt. Analisa bentuk permukaan patahan (fracture surface) diperlukan untuk menentukan penyebab terjadinya perpatahan seperti ditunjukkan dalam [2]-[10], dan kondisi spring bolt. 


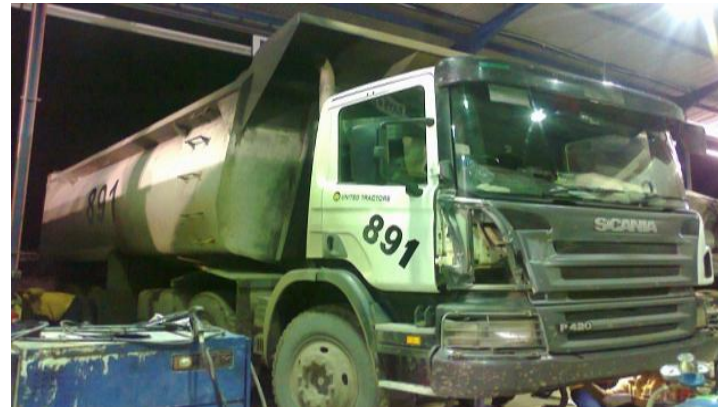

Gambar 1. Unit yang mengalami perpatahan spring bolt pada front leaf spring

Zamanzadeh dkk [11] melakukan investigasi terhadap patahnya bolt pada poros roda truk trailer. Berdasarkan hasil analisa diketahui bahwa penyebab patahnya bolt dikarenakan bending atau reverse bending fatik. Ulir bolt merupakan konsentrasi tegangan alami, dan menjadi tempat dimulainya retakan.

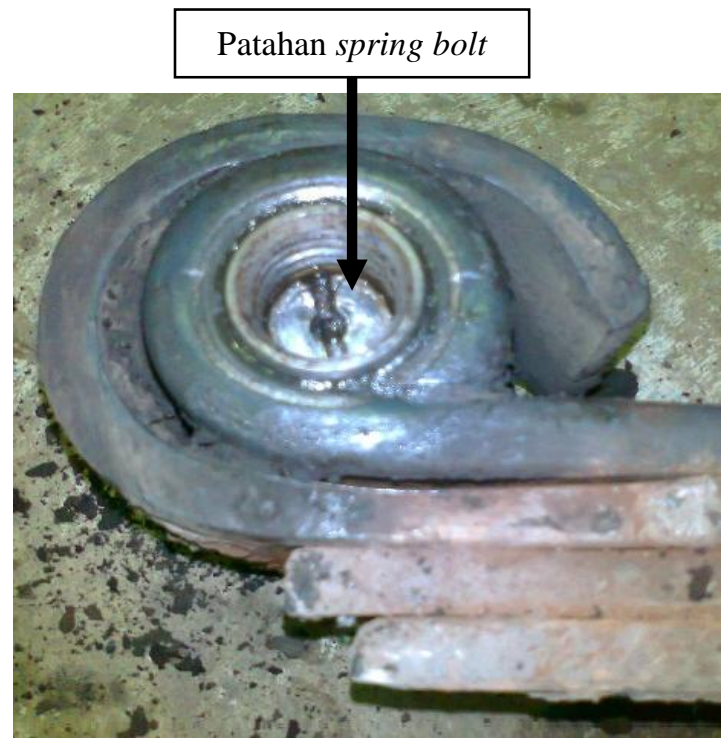

Gambar 2. Patahan spring bolt di dalam bushing spring

\section{Metoda Penelitian}

Metoda yang digunakan untuk dapat menemukan akar penyebab patahnya spring bolt pada front leaf spring adalah pengumpulan data lapangan, dokumentasi lapangan, dan pengumpulan komponen yang mengalami perpatahan.

\section{Hasil Penelitian}

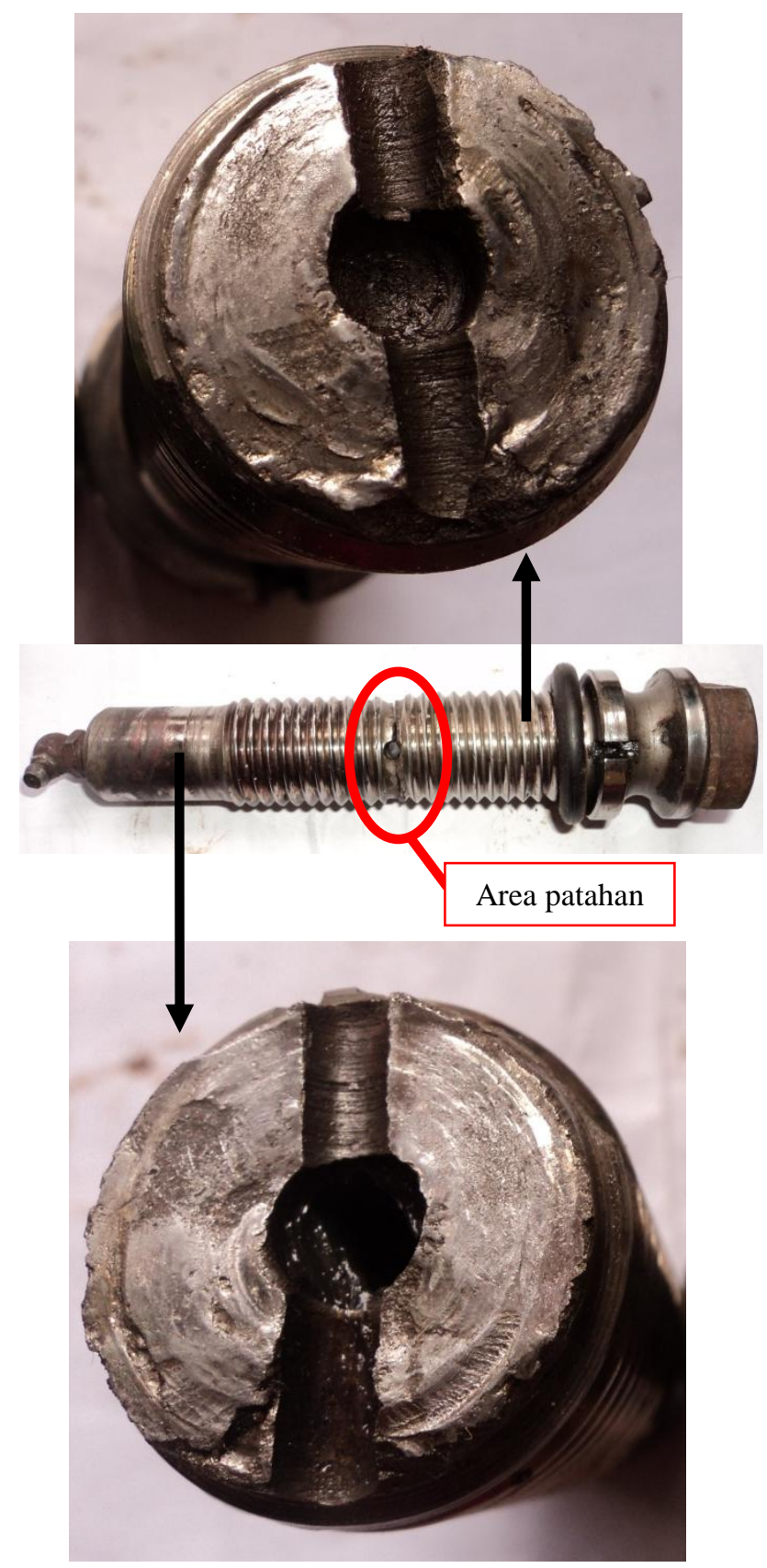

Gambar 3. Patahan spring bolt dan bentuk permukaan patahan

Patahan spring bolt dan bentuk permukaan patahan ditunjukkan dalam Gambar 3. Spring bolt mengalami perpatahan di bagian tengah, yang merupakan jalur distribusi grease. Permukaan patahan secara mayoritas menunjukkan permukaan yang halus (smooth texture). Selain itu tampak adanya 
area dari patahan seperti terolesi (smearing apparent) dan area final fracture tidak tampak secara jelas. Fenomena ini menunjukkan bahwa terjadi perpatahan akibat torsional shear [12]. Pembebanan yang terjadi secara single overload.

Terdapat beberapa faktor yang menjadikan spring bolt mengalami single overload. Berdasarkan Gambar 4 menunjukkan bahwa nipple string bolt mengalami kebuntuan sehingga proses pelumasan tidak terjadi. Tidak terjadinya pelumasan akan mengurangi life time spring bolt karena mengalami penurunan kualitas (poor durability). Pelumasan diperlukan diantara 2 bagian benda yang saling bergesekan (kontak), yang bertujuan untuk mengurangi tingkat gesekan, laju keausan, mengurangi panas, dan kotoran [13]. Secara konstruksi, spring bolt terletak didalam bushing untuk mengunci dan menopang leaf spring pada front spring bracket, seperti ditunjukkan dalam Gambar 5. Jenis pelumasan yang digunakan berupa grease. Pengunaan pelumas jenis grease dikarenakan [13]:

- memberikan efek pelumasan yang baik terhadap pemakaian dalam kondisi ekstrim, seperti beban kejut (shock loading), high speed, low speed;

- melindungi dari kontaminasi;

- melindungi komponen dari air;

- grease memiliki gaya lekat (adhesion) yang baik terhadap bagian yang dilumasi;

- tidak menetes dan tidak memercik;

- memperpanjang life time komponen yang mengalami keausan.

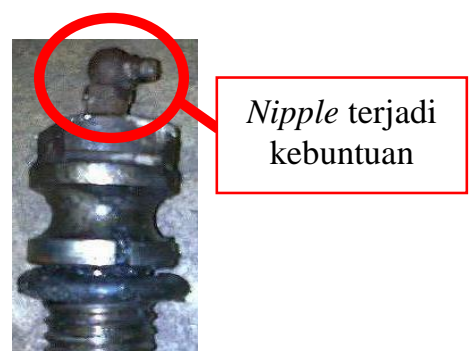

Gambar 4. Nipple spring bolt mengalami kebuntuan
Seiring dengan penurunan kualitas spring bolt akibat tidak adanya pelumasan, maka ketika terjadi pembebanan diatas kekuatan bahan spring bolt menyebabkan terjadinya single-overload. Kondisi jalan tambang yang banyak menanjak dan tidak rata, serta unit yang bermuatan mendukung terjadinya single overload terhadap spring bolt.

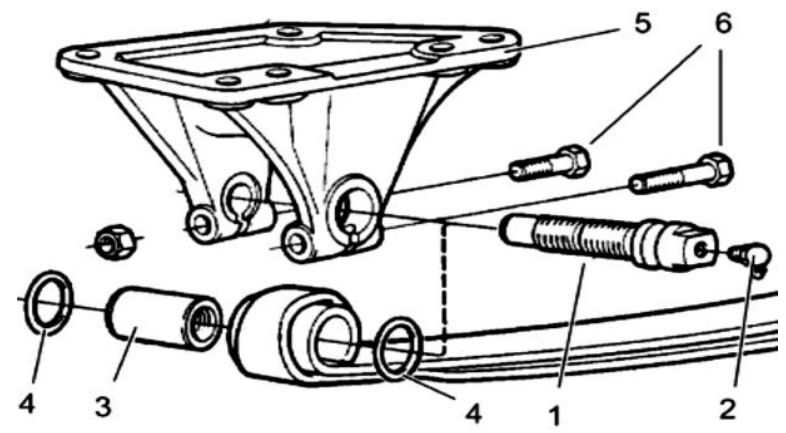

Gambar 5. Konstruksi spring bolt (nomor 1) dalam rangkaian front leaf spring

Spring bolt sebagai pengunci leaf spring dapat mengalami gaya statik berupa torsi, geser, tarik, atau bending, dan juga gaya dinamik berupa fatigue (termasuk getaran), atau kejut [12]. Sesuai dengan fungsi suspensi yaitu menopang kendaraan, meredam kejutan, dan menstabilkan kendaraan terhadap permukaan jalan, sehingga hanya gaya-gaya tersebut yang dapat menyebabkan perpatahan spring bolt. Ilustrasi pembebanan yang terjadi pada leaf spring (berpengaruh terhadap spring bolt) seperti diperlihatkan Gambar 6 .

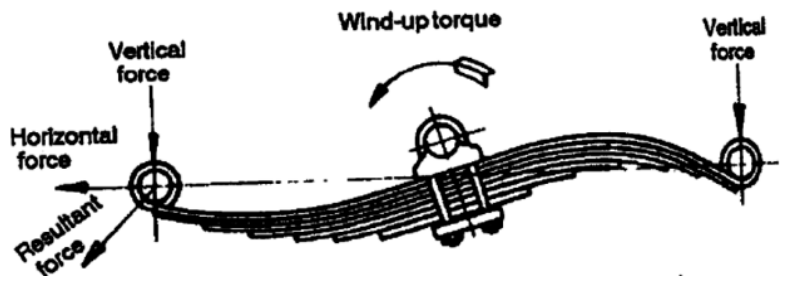

Gambar 6. Gaya-gaya yang terjadi pada leaf spring

Berdasarkan Gambar 7 posisi patahan spring bolt terjadi di groove dekat ulir. Bagian tersebut merupakan bagian terlemah komponen, yang apabila terjadi peningkatan 
tegangan dapat menyebabkan perpatahan. Terjadinya penurunan kekuatan komponen dikarenakan bagian groove dan ulir merupakan daerah konsentrasi tegangan (stress raiser) [12]. Gambar 8 menunjukkan ilustrasi peningkatan konsentrasi tegangan akibat adanya groove dan ulir.

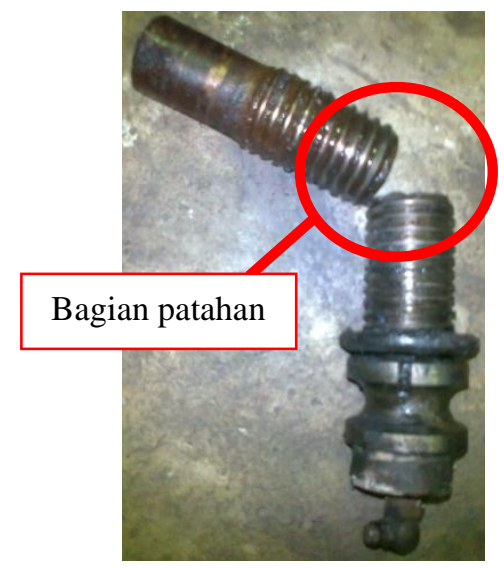

Gambar 7. Bagian terjadinya perpatahan pada spring bolt

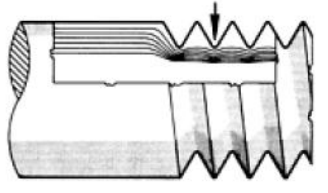

(A)

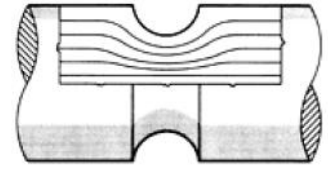

(B)
Gambar 8. Konsentrasi tegangan pada: (A) ulir; (B) groove [12]

\section{Kesimpulan}

Analisa bentuk permukaan patahan spring bolt pada front leaf spring menunjukkan bahwa adanya torsional shear yang menyebabkan patahnya spring bolt. Pembebanan yang terjadi secara singleoverload. Faktor-faktor yang mempengaruhi perpatahan akibat single-overload dikarenakan tidak adanya pelumasan. Selain itu kondisi jalan yang banyak menanjak, dan tidak rata serta unit yang bermuatan menunjang terjadinya pembebanan secara single-overload. Posisi patahan spring bolt terjadi di groove dan dekat ulir karena merupakan bagian yang memiliki konsentrasi tegangan tinggi.

\section{Saran}

Diperlukan adanya analisa lebih lanjut terkait patahnya spring bolt pada front leaf spring seperti analisa unsur, struktur mikro, pengamatan SEM, dan uji bahan spring bolt.

\section{Daftar Pustaka}

[1] G. Genta and L. Morello, "The automotive chassis," in Mechanical Engineering Series (Components Design, vol. 1), Springer Science+Business Media B.V., 2009, pp. 133-134.

[2] D. Ghosh et al., "Failure investigation of condensate pump shaft," J. of Failure Anal. \& Preven., vol. 14, pp. 450-453, 2014.

[3] Z. Lei et al., "Torque converter turboshaft fracture failure analysis and improvement," Appl. Mechanics and Materials, vol. 571572, pp. 1087-1090, 2014.

[4] P. Sharma, "Premature failure of ductile iron pump impeller in cooling tower system," J. of Failure Anal. \& Preven., vol. 14, pp. 303306, 2014.

[5] R. K. Mishra and J. Thomas, (2014). "Investigation of compressor failure in a military turbojet engine," J. of Failure Anal. \& Preven., vol. 14, pp. 443-449, 2014.

[6] R. K. Mishra et al., "Investigation of LP turbin blade failure in a low bypass turbofan engine," J. of Failure Anal. \& Preven., vol. 14, pp. 160-166, 2014.

[7] S. Das et al., "Failure Analysis of axle shaft of a fork lift," Case Stud. in Eng. Failure Anal., vol. 3, pp. 46-51, 2015.

[8] S. S. Pelaseyed et al., "Investigation of the shaft failure connected to extruder," J. of Failure Anal. \& Preven., vol. 15, pp. 775781, 2015.

[9] M. Sujata and S. K. Bhaumik, "Fatigue fracture of a compressor blade of an aeroengine: what caused this failuire," J. of Failure Anal. \& Preven., vol. 15, pp. 457463, 2015.

[10] E. Zdravecka et al., "Failure analysis of the pulleys during the press-fit assembling process," Case Stud. in Eng. Failure Anal., vol. 3, pp. 34-38, 2015.

[11] M. Zamanzadeh et al., "Fatigue failure analysis case studies," J. of Failure Anal. \& Preven., vol. 15, pp. 803-809, 2015. 
[12] ASM Handbook-Failure Analysis and Prevention, vol. 11, Print Volume, ASM International, 2002, pp. 1497-1498, 1504.

[13] ASM Handbook-Friction, Lubrication, and Wear Technology, vol. 18, Print Volume, ASM International, 1992, pp. 123, 219. 